\title{
Dynamic Learning Networks
}

\section{Models and Cases in Action}




\section{Dynamic Learning Networks}

\section{Models and Cases in Action}

Edited by

Aldo Romano

Giustina Secundo

University of Salento

Lecce, Italy

望 Springer 


\section{Editors}

Aldo Romano

e-Business Management Section of

Scuola Superiore ISUFI

University of Salento

c/o Euro Mediterranean Incubator

Campus Ecotekne Via per Monternoi

s.n 73100 Lecce, Italy

aldo.romano@unile.it
Giustina Secundo

e-Business Management Section of Scuola Superiore ISUFI

University of Salento

c/o Euro Mediterranean Incubator

Campus Ecotekne Via per Monternoi, s.n 73100 Lecce, Italy

giusy.secundo@ebms.unile.it

ISBN 978-1-4419-0250-4

e-ISBN 978-1-4419-0251-1

DOI 10.1007/978-1-4419-0251-1

Springer Dordrecht Heidelberg London New York

Library of Congress Control Number: 2009926316

(C) Springer Science+Business Media, LLC 2009

All rights reserved. This work may not be translated or copied in whole or in part without the written permission of the publisher (Springer Science+Business Media, LLC, 233 Spring Street, New York, NY 10013, USA), except for brief excerpts in connection with reviews or scholarly analysis. Use in connection with any form of information storage and retrieval, electronic adaptation, computer software, or by similar or dissimilar methodology now known or hereafter developed is forbidden.

The use in this publication of trade names, trademarks, service marks, and similar terms, even if they are not identified as such, is not to be taken as an expression of opinion as to whether or not they are subject to proprietary rights.

Printed on acid-free paper

Springer is part of Springer Science+Business Media (www.springer.com) 


\section{Acknowledgements}

We would like gratefully acknowledge some people, without whom this book has not been possible.

First, the Scientific Committee of the Advanced International Summer School, 2008 session, on "Managing Uncertainty and Competition Through Dynamic Learning Networks" of eBMS-Scuola Superiore ISUFI, University of Salento (IT) for having organized and led the research tracks and discussions in which the book contributions are developed. A special gratitude goes to Prof. Ernesto Damiani of University of Milan that provided us the right energy and direction to start this project. Moreover, a special thank to the chapters' authors for their enthusiasm and punctuality in providing their contributions and last but not the least, Dr. Claudio Petti for his valuable comments and insights for the organization of the work. 


\section{Contents}

Acknowledgements .......................................................................................

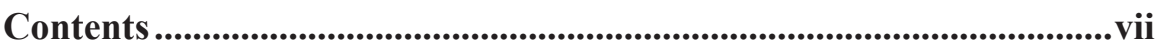

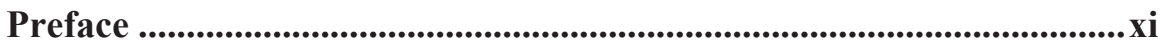

List of contributing authors .........................................................................xiii

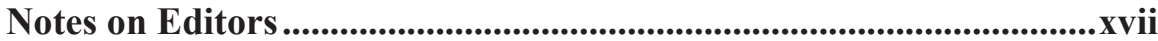

Notes on contributing authors ...................................................................xix

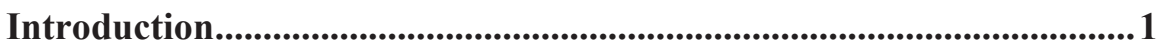

by Aldo Romano, Giustina Secundo

An integrated perspective on Dynamic Learning Networks.................... 1

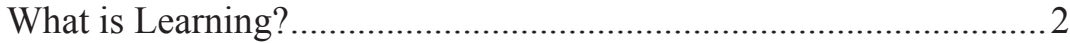

What is Network and Learning in network?....................................... 4

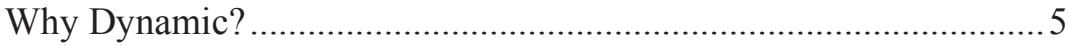

Defining Dynamic Learning Networks .............................................. 6

Dynamic Learning Networks design variables and typology .............. 7

Structure and contents of the book .................................................... 9

Key features and guiding principles ............................................... 16

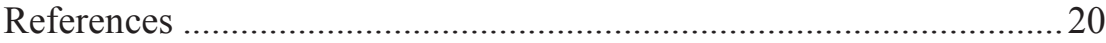

Chapter 1. Networks for manage change in international commercial organisations ......................................................................................223

by Tom Osorio

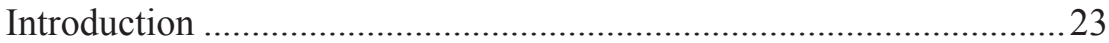

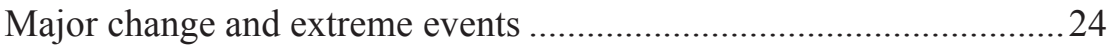

Organisational Complexity or Complication .......................................25

Research challenges in the hydrocarbon exploration industry: Shell case study 
Changing a consultancy from partnership to public company: Scott Wilson case study

Effective medium term responses to a major event in an International

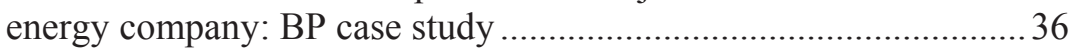

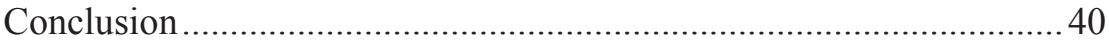

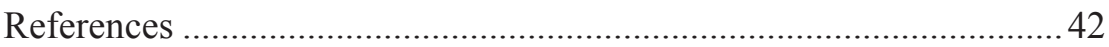

\section{Chapter 2. The Relevance of Organizational Learning for High}

Performing Social Networks .........................................................................43 by Jeff Clanon

Organizational Learning: Historical Perspective . .43

Learning from Research on "Hastily Formed Networks" ..................... 47

Introduction: The Hastily Formed Networks (HFN) Project.............47

Core Research Questions.................................................................. 48

Findings: How action was mobilized throughout the network ......... 49

What minimal organization structures are required..........................4 49

Preconditions that are necessary for Hastily Formed Networks to be

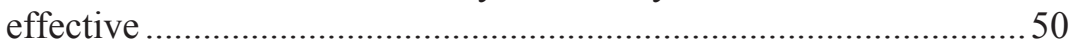

The leadership capabilities and characteristics required.......................50

The Relevance of Organizational Learning for High Performing Social

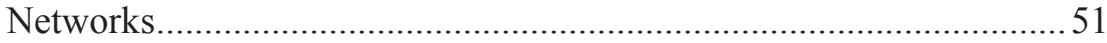

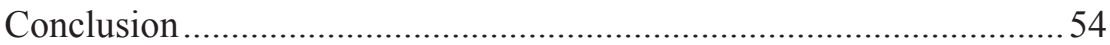

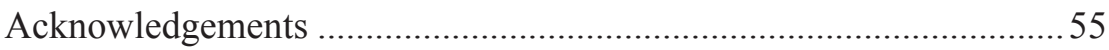

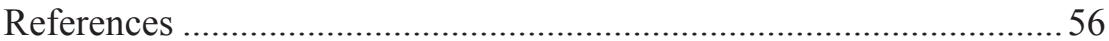

Chapter 3. illycaffè and the Brazilian espresso knowledge network...57 by Ingrid Rauscher, Pierpaolo Andriani

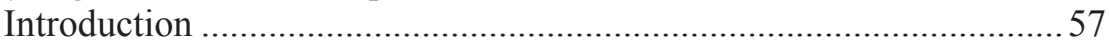

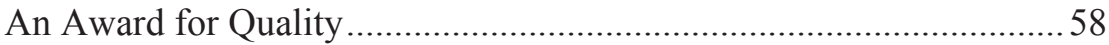

A network for generating and disseminating knowledge ...................... 61

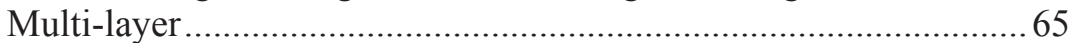

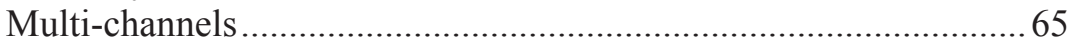

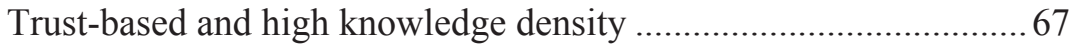

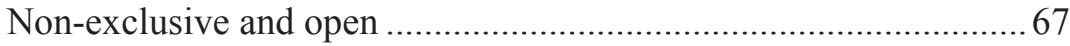

The insertion of coffee in the information and knowledge economy ... 68

Final considerations - Changing the landscape through knowledge.... 70

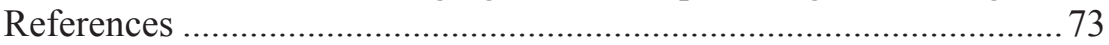

Chapter 4. Learning dynamics within the solutions network............... 75

by Stefano Miraglia, Andrew Davies

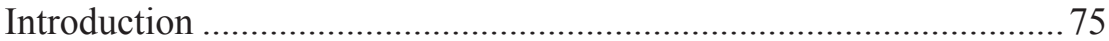

Integrated solutions: a collaborative business model .......................... 76 
The shift toward solutions: origins, drivers and recent evolution.....76

Refocusing the business and reorganizing for customer-centricity .. 78

Capability building and organizational learning...............................79

Learning dynamics within the solutions business model.......................8 80

The configuration of the necessary capabilities................................. 80

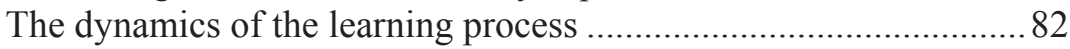

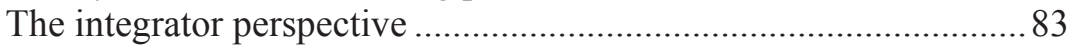

The supplier-customer interface: emphasis on the front-end............ 84

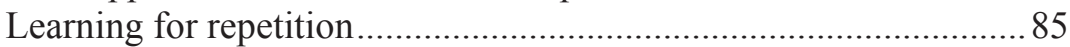

The customer perspective: feeding the learning process .................. 86

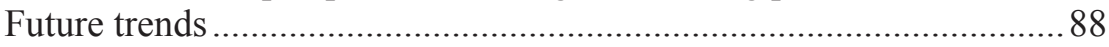

Getting ready for environmental changes: network proactivity .......88

Toward complete integration........................................................... 90

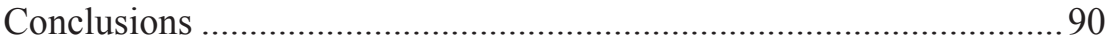

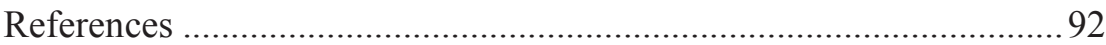

\section{Chapter 5. Towards "Stakeholder University" as dynamic learning} network: the Finmeccanica case.

by Roberto Maglione, Giuseppina Passiante

Challenging the new Competitive Landscape: the emerging Networked

Learning Organizations …................................................................ 95

The central role of Human Capital in Networked Learning

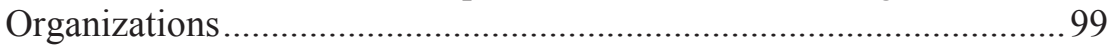

The emerging pedagogical approaches for creating Human Capital.. 101

Towards the Stakeholder Universities for creating suitable Human

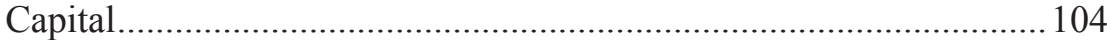

Creating human capital in Finmeccanica Group: towards the

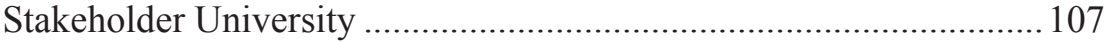

The start-up: the Finmeccanica Virtual Corporate University........ 108

Towards the Finmeccanica Stakeholder University: open issues... 112

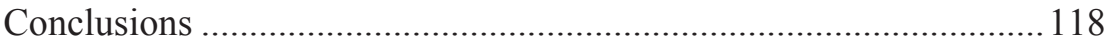

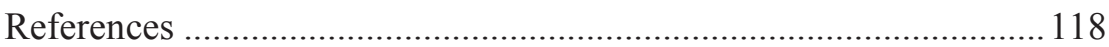

\section{Chapter 6. Expanding the Value of Corporate Universities: The}

Stakeholder Approach.

by Mark Allen

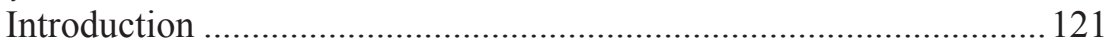

The history and evolution of corporate universities .......................... 122

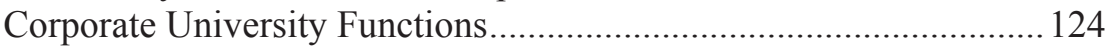

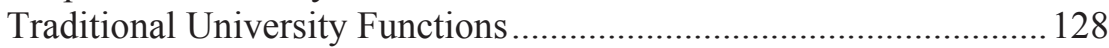

Stakeholders of Traditional Universities ........................................... 128

Stakeholders of Corporate Universities ................................................ 129 
The Value of the Stakeholder Approach ............................................. 132

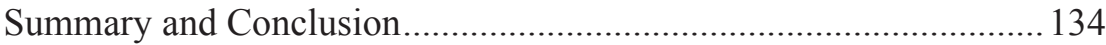

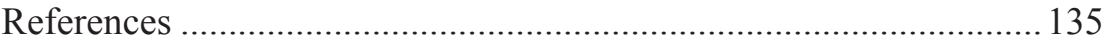

\section{Chapter 7. Corporate Universities 2.0: The Future Networked} Learning Organization ................................................................................... 137

By Jeanne C Meister

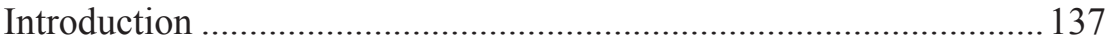

A Worldwide Shift in Demographics .............................................. 138

Corporate Universities: A Target in Tough Economic Times? ........... 138

The Era of Social Computing Arrives ............................................. 139

Personal Broadcasting Leads To Personalized Learning.................. 141

Sophistication of Mobile Phones Allows For Mobile Learning ..... 141

The Emergence of Corporate Universities 2.0 …............................ 142

Corporate Universities 2.0 In Action.............................................. 144

Corporate Universities 2.0: Blending Learning with Working ...... 144 Corporate Universities 2.0: From Cerner Virtual University To Cerner

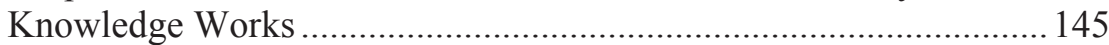

Becoming A Corporate University 2.0 ….................................... 147

Implications for Corporate Universities ......................................... 148

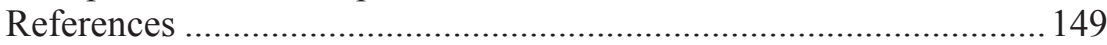

\section{Chapter 8. Emergent management learning in dynamic learning} networks....................................................................................................................... 151

by Walter Baets

Complexity emergence and a quantum interpretation of business ..... 151

On to biology: Sheldrake and "implicit order".................................. 152

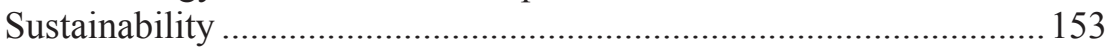

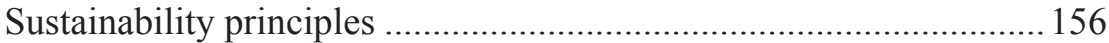

A holistic model............................................................................ 157

Applied to management: A systemic management interpretation .......159

Leadership: the driving force of sustainability .................................. 163

Summary description of the Innovation School and its conceptual model: sustaining learning networks in corporations .......................... 164

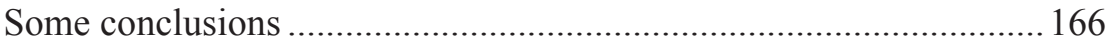

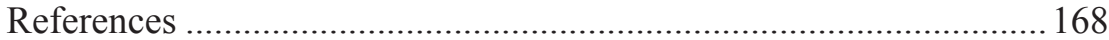

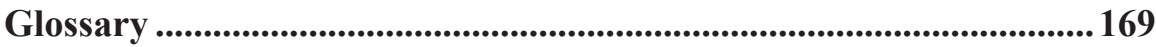

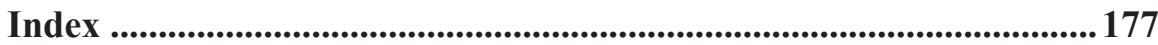




\section{Preface}

When a firm moves into a new technology or market base developing complex and integrated products and solutions, it needs dynamic process of building capability over time. For this purpose firms have to rely on information and knowledge, creating new managerial roles to deal with uncertainty and competition. Their adaptive dynamic aim is to create sustainable sources of competitive advantage: as a consequence, firm centric model of learning are inadequate and should be more and more supported by network learning and learning networks. The diffusion of networks is generating a new context for organisational learning. These processes are therefore "sine qua non" condition for firm's strategy and become important vehicles for managing emergent strategies. And that is where this book comes in, presenting an integrative view on dynamic learning networks. Just as the focus of computing in recent years has moved from the node to the network, learning networks possess the potential to harness greater efficiencies and greater capacities (both in individuals, organizations and inter-organisation). In other words firms must develop processes to:

- integrate learning that occurs at the core and multiple edges of organizations

- combine learning that takes place at individual, organizational and interorganizational and network levels

- organize themselves in networked form to manage the uncertainty and the complexity of the competitive environment.

By connecting people in networks, we can leverage learning in organizations, and by networking organizations, we can exponentially expand the reach and value of learning. To compete "on the edge" organizations have to learn "on the edge".

The book represents an attempt to provide a network perspective of organisational learning to drive dynamic competition through extended firm learning processes, exploring enabling and constraining mechanisms associated with effective learning in networks. 
This book draws on topics related to discussions from the $10^{\text {th }}$ session of the Advanced International Summer School on "Managing Uncertainty and Competition Through Dynamic Learning Networks" held in July 3rd5th, 2008 in Ostuni and organised by the e-Business Management Section of the Scuola Superiore ISUFI (University of Salento, Italy).

\section{Target Audience}

Dynamic Learning Networks: Models and cases in action is a book targeting three categories of readers:

- business strategists providing them with a conceptual framework and a set of guidelines for the development of learning networks as a key process to lead change in complex environments;

- academics through insights and best practices for analyzing learning processes in terms of different literature perspectives including organizational development, strategic management and organizational learning;

- practitioners and consultants, providing them with a holistic view of emerging trends in dynamic learning processes arising in network context, whose nodes are partners, suppliers, users, customers, employees, teams and organization, depicting the emergence of the nextgeneration's learning organizations.

We are interested in hearing your comments about this book. In times of proliferating management bibles, roadmaps and receipts for success, our objective is to share with the reader our belief that in management, as in life, everything starts with Learning, Interaction and Networks. We hope you enjoy the journey.

Aldo Romano (aldo.romano@unile.it) Giustina Secundo (giusy.secundo@ebms.unile.it)

Lecce, February 2009 


\title{
List of contributing authors
}

\author{
Mark Allen \\ Pepperdine University, 6100 Center Drive \\ Los Angeles, CA 90045, USA \\ 001-310-568-5593 \\ mallen@pepperdine.edu
}

Pierpaolo Andriani

Associate Professor

eBMS, Scuola Superiore ISUFI, University of Salento,

Campus Ecotekne, Via per Monteroni, 73100 Lecce, IT

pierpaolo.andriani@durham.ac.uk

Walter Baets

Associate Dean for Innovation and Social Responsibility

Euromed Marseille, Ecole de Management

Domaine de Luminy

BP 92113288 Marseille Cedex 9 13288, FR

Walter.Baets@euromed-management.com

Jeff Clanon

Founding Consultant Member

Society for Organizational Learning

151 Hubbard Street

Concord, Ma, USA

jclanon@solonline.org

Andrew Davies

Reader in Innovation Management

Imperial College Business School

Exhibition Road, SW7 2AZ London, UK

a.c.davies@imperial.ac.uk 
Jeanne C. Meister

Founder, New Learning Playbook Blog

1501 Broadway, Suite 800,

New York, NY, 10036, USA

jeanne@newlearningplaybook.com

jeanne@jeannemeister.com.

Roberto Maglione

Executive Vice President Human Resources

Finmeccanica Group

Piazza Monte Grappa, 4 - 00195 Roma, IT

roberto.maglione@finmeccanica.com

Stefano Miraglia

PhD Student

eBMS, Scuola Superiore ISUFI, University of Salento,

Campus Ecotekne, Via per Monteroni, 73100 Lecce, IT stefano.miraglia@ebms.unile.it

\section{Tom Osorio}

Safety \& Operations, BP

Mill Farm House, Ravensworth,

Richmond, North Yorkshire, DL11 7EU, UK

Tom.Osorio@uk.bp.com

Giuseppina Passiante

Full Professor

eBMS, Scuola Superiore ISUFI, University of Salento, Campus Ecotekne, Via per Monteroni, 73100 Lecce, IT giuseppina.passiante@unile.it

Ingrid Rauscher

Director

ADS Assessoria de Comunicações Ltda

Rua Michigan, 69 São Paulo, Brazil

ingridr@adsbrasil.com.br 
Aldo Romano

Full Professor and Director eBMS, Scuola Superiore ISUFI, University of Salento, Campus Ecotekne, Via per Monteroni, 73100 Lecce, IT aldo.romano@unile.it

Giustina Secundo

Assistant Professor and Researcher eBMS, Scuola Superiore ISUFI, University of Salento, Campus Ecotekne, Via per Monteroni, 73100 Lecce, IT giusy.secundo@ebms.unile.it 


\section{Notes on Editors}

Aldo Romano (Editor and Author) is Full Professor of Innovation Management at the Faculty of Engineering and Director of Scuola Superiore ISUFI at the University of Salento (Lecce, Italy). He is also President of DHITECH, a Technological District in the Apulia region and former President of the Italian Technical-Scientific Commission. Aldo Romano's activities have three general areas:

- Research in High Energy Physics at the Department of Physics at University of Bologna and University of Bari (Italy). He has participated in numerous scientific experiments at the European Organization for Nuclear Research (CERN) in Geneva.

- Scientific, cultural, and political commitment to the development of innovation, especially in the south of Italy. In 1981, as Visiting Professor at the Stanford University (California-USA), he studied the phenomenon of Silicon Valley. This experience represented the basis for the foundation of the First Italian Scientific and Technological Park (Tecnopolis Novus Ortus) in 1984.

- Scientific and operative commitment to issues concerning Internetenabled organizational changes, with special reference to the analysis of the "Digital Divide."

This scientific activity has been documented in different books, among these Creating Business Innovation Leadership (Edizioni Scinetifiche Italiane, 2001), Costruire l'Università post Fordista. Sperimentare il futuro nel presente (Cacucci Editore, 2008) and Open Business Innovation Leadership. The Emergence of the Stakeholder University, (Palgrave, UK 2009).

Aldo Romano is the author of many books and publications in international journals and leading conference proceedings. In acknowledgment of his scientific achievements, Aldo Romano has been awarded the Gold Medal of Merit for Culture, School and Arts from the President of the Italian Republic. 
Giustina Secundo (Editor and Author) is Assistant Professor and Researcher in Management Engineering at the e-Business Management Section (eBMS) of Scuola Superiore ISUFI at the University of Salento (Lecce, Italy). She holds a MSc in "e-Business Management" from the same institution.

Giustina Secundo performs scientific research in "Learning, Innovation and Value Network" field with a particular focus on Learning Engineering Systems at individual, organizational, inter-organizational and network Level, ICTs based. Her research attests the extensive development in learning processes, technologies and innovative pedagogy in higher education, focused on:

- Learning Strategies and Processes for human capital creation (competency based) in Universities and Business Schools supported by ICTs

- Processes of Corporate Learning for Organisational Development, involving multiple stakeholders within the networked enterprise

- Modelling and development of learning environments enabled by Web 2.0 technologies.

These research activities have been documented in many books' chapters, among these Open Business Innovation Leadership. The Emergence of the Stakeholder University, (Palgrave, UK 2009), publications in international journals and leading conference proceedings.

Her scientific output is the result of 9 years experience in the management of Higher Education programs at eBMS, where since 2000 she:

- Coordinates the planning and the entire scientific organization of the annual session of the Advanced International Summer School on "eBusiness and Complexity: New Management Practices"

- Coordinates the activities of the International Master in "e-Business Management ", one year and full time in collaboration with Al Akhawayn University in Ifrane Morocco, devoted to students coming the Southern Mediterranean Countries (mainly Morocco, Jordan and Tunisia);

- Coordinates and teaches at the Undergraduates courses of level I and II of the eBMS at Scuola Superiore ISUFI.

Since 2000, she is lecturer for the course "Management of Innovation and projects" and "Economics and Management of Innovation" at the Faculty of Engineering University of Salento. Finally she is tutor for the students of Ph.D. program in "e-Business" and she teaches "Knowledge Management" and "Innovation Management" for the International Master Program in "e-Business Management" at eBMS. 


\section{Notes on contributing authors}

Mark Allen, Ph.D., is the editor and co-author of The Corporate University Handbook and The Next Generation of Corporate Universities. He is on the faculty of Pepperdine University's Graziadio School of Business and Management in Malibu, California. He serves as a consultant to new and mature corporate universities.

Pierpaolo Andriani, Ph.D., is Senior Lecturer in Innovation Management at Durham Business School, UK and Associate Professor at the eBusiness Management Section (eBMS) of Scuola Superiore ISUFI, University of Salento, Italy. His research interests are focused on the impact of complexity theory on organizational theory, industrial clusters and innovation.

Walter Baets is Associate Dean for Innovation and Social Responsibility, and professor Complexity, Knowledge and Innovation at Euromed Marseille - Ecole de Management. He graduated in econometrics and operations research at the University of Antwerp (Belgium) and was awarded a $\mathrm{PhD}$ from the University of Warwick in Industrial and Business Studies (UK) and a HDR (Habilitation a diriger des recherches en science de la gestion) from IAE Aix-en-Provence, University Paul Cezanne, AixMarseille III (F).

Andrew Davies is Reader in Innovation and Entrepreneurship Group at the Imperial College Business School, London. He is a co-director of the EPSRC Innovation Studies Centre and theme leader of research on 'project business'. Andrew has published many articles in leading journals. His two recent books include The Business of Projects: Managing Innovation in Complex Products and Systems, Cambridge University Press (2005), coauthored with Michael Hobday, and The Business of Systems Integration, Oxford University Press (2003, 2005), co-edited with Andrea Prencipe and Michael Hobday. 
Roberto Maglione, Executive Vice President Human Resources of Finmeccanica Group. He held positions of increasing responsibility including: HR Manager of Sky Italia, Telecom Italia Group, Tim and Olivetti Group. He is Vice President of Federmeccanica Europe and President of the Federation of European Entrepreneurs in the mechanical engineering sector (CEEMET).

Jeanne C. Meister is an executive consultant, speaker, and creator of the popular blog New Learning Playbook, www.newlearningplaybook.com Jeanne is also the author of Corporate Quality Universities as well as Corporate Universities: Lessons in Building a World-Class Work Force. Jeanne is writing a new book on innovations in the workplace. Jeanne can be reached at www.jeannemeister.com.

Stefano Miraglia is $\mathrm{PhD}$ candidate at the e-Business Management Section (eBMS) of the Scuola Superiore ISUFI, University of Salento, Lecce (Italy), currently visiting at Imperial College Business School, London (UK). His research focuses on the integration of products, services and technologies for the provision of customer solutions and the use of platforms for the modularization and replication of solutions architectures in capital goods.

Tom Osorio is Fellow of the Institution of Mechanical Engineers. Tom Osorio has worked internationally as a senior manager and director in petrochemicals, consultancy and oil energy industry. His interest is in improving management of high consequence low probability risks, using strategies ranging from technical improvements to leadership development. Research includes reconciling cultural differences in operations management and major organisational change in high reliability organisations.

Giuseppina Passiante is Full Professor of Innovation Management at the Department of Innovation Engineering of the University of Salento (Italy). She is coordinator of the research area on Open Networked Business Management at the Euro-Mediterranean Incubator in Business Innovation Leadership of Scuola Superiore ISUFI - University of Salento (Italy). Currently her research fields concern the management of learning organizations and learning processes in the Net-Economy. Her focus is mainly on the development of Intellectual Capital, both in entrepreneurial and academic organizations. She is also expert in the development of local systems, and complexity in economic systems. In these research fields she has realized programs and projects, and published several papers. 
Ingrid J. Rauscher, partner and director of ADS Assessoria de Comunicações, São Paulo (SP), Brazil, public relations agency responsible for the work developed for the Italian roaster illycaffè in Brazil, winner of the Golden World Award, from the International Public Relations Association and the most prestigious ABERJE 2007 award in the category of "Corporate Communications with Suppliers". 